\title{
OPTIMIZATION STUDY ON EXTRACTION \& PURIFICATION OF PHYCOERYTHRIN FROM RED ALGAE KAPPAPHYCUS ALVAREZII
}

\author{
SHARMILA BANU VM ${ }^{1}$, SANTHOSH $\mathrm{S}^{2}$, HEMALATHA $\mathrm{V}^{1}$, VENKATAKRISHNAN $\mathrm{V}^{3}$, DHANDAPANI $\mathbf{R}^{1 *}$ \\ ${ }^{1}$ Fermentation Technology Laboratory, Department of Microbiology, Periyar University, Salem - 636011, Tamil Nadu, India. ${ }^{2}$ Applied \\ Microbiology Laboratory, Department of Microbiology, Periyar University, Salem - 636 011, Tamil Nadu, India. ${ }^{3}$ Department of Food \\ Science and Technology, Pondicherry University, Pondicherry - 605014, India. Email: danpani@gmail.com
}

Received: 09 October 2016, Revised and Accepted: 19 October 2016

\section{ABSTRACT}

Objective: The current study focuses on R-Phycoerythrin pigment production from Seaweed using different chemical and physical conditions.

Methods: In the present study Seaweed was collected from Rameshwaram and identified by CS-MCRI Institute, Mandapam. The collected seaweed was then washed using distilled water for further processing. Using a sterile knife the seaweed was cut into small pieces. The chopped seaweeds were then weighed and subjected to different optimization procedures for pigment production. These equally weighed seaweeds were treated with three varying Buffers at different $\mathrm{pH}$, the buffer showing better O.D value was subjected to different Cell disruption techniques and finally freeze thawed at different temperature stress.

Results: The seaweeds were subjected to different chemical and physical stress conditions for R-phycoerythrin production. On optimizing the different buffer solutions for pigment production Sodium phosphate buffer showed maximum O.D of 0.215 when compared to other buffers whereas on providing different $\mathrm{pH}$ conditions the O.D value obtained was high at $\mathrm{pH}$ 7.2. Different cell disruption techniques were followed for pigment production using the sodium phosphate buffer at $\mathrm{pH} 7.2$ and freeze thaw method was found suitable for the highest pigment production with 0.D value of 0.441 . Hence after optimization of different extraction procedures, cell disruption followed by freeze \& thaw method $\left(-20^{\circ} \mathrm{C}\right.$ and $\left.25^{\circ} \mathrm{C}\right)$ showed maximum R-phycoerythrin content.

Conclusion: From the findings, it was also observed that the primary metabolites produced by these organisms may serve as potential bioactive compounds of interest in the Food industries as natural colourant and in cosmetic industries.

Keywords: Seaweeds, Extraction, Phycoerythrin, Optimization, Cell disruption, Sonication.

(c) 2017 The Authors. Published by Innovare Academic Sciences Pvt Ltd. This is an open access article under the CC BY license (http://creativecommons. org/licenses/by/4. 0/) DOI: http://dx.doi.org/10.22159/ajpcr.2017.v10i2.15598

\section{INTRODUCTION}

The red algae or Rhodophyta or from Ancient Greek: "Rose" and "plant" are one of the oldest groups of eukaryotic algae and also one of the largest, with about 5000-6000 species of mostly multicellular, marine algae, including many notable seaweeds. Red algae, Kappaphycus alvarezii (Doty) Doty ex P.C. Silva originally comes from the Philippines and, currently, it has spread all over the world [1]. These species are first introduced in Indonesia in 1985 and became popular as one of the potential marine aquaculture products [2]. In 2010, Indonesia has reached the second position as highest productivity of seaweed in the world. To make alternative option in the developing $K$. alvarezii economical value by different products, its biomass availability is critical especially in Indonesia.

K. alvarezii was used for its various nutritional products including antioxidant or a nutraceutical supplement. Machado et al. [3] found that the predominant sterol was desmosterol in red seaweeds (87-93\% of total sterol content). K. alvarezii an economically, important red tropical seaweed, which is highly demanded its cell wall polysaccharide, is the most important source of kappa carrageenan Mc Hugh [4]. The world production of Kappaphycus species is approximately 28000 tons per annum. This seaweed accounts for the largest consumption worldwide [5].
Rajasulochana et al. [6] and Fayaz et al. [7] suggested the utility of K. alvarezii for various nutritional products including antioxidant for use as health food or nutraceutical supplement. Machado et al. [3] found that the predominant sterol was desmosterol in red seaweeds (87-93\% of total sterol content). Omer [8] confirmed that fatty acids and sterol of algal class, families and sometimes even species are characteristics to those particular taxa and could be useful as chemotaxonomic. Cholesterol generally plays a structural role in the cell membrane. Clinical studies have demonstrated that dietary intake of plant sterols (as part of the normal diet, or as a supplement) may help reduce blood cholesterol levels. Sterols are thus among the nutritionally important lipids that need to be routinely determined in foods [9].

Phycoerythrin (PE) is a protein acting as a photosynthetic accessory pigment in red algae (Rhodophyta). This protein has gained many biotechnological applications in food science, cosmetics, and analytical processes [10]. R-phycoerythrins (R-PEs) are the most abundant phycobiliproteins in the marine red algae. Phycobilisome composed of phycobilin chromophores (PE, phycocyanin, and allophycocyanin) associated with proteins. PE appears red and phycocyanin range from purple (phycoerythrocyanin, R-phycocyanin) to deep blue (C-phycocyanin) and allophycocyanins are blue with a hint of green. Phycobiliproteins are used as colorants in food (chewing gums, dairy products, ice sherbaths, gellies, etc.,) and cosmetics such as lipstick and eyeliners in Thailand, Japan, and China. 
R-PE possesses yellow fluorescence. It has also been tested in lollipop, dry sugar candies for cake decoration, soft drinks, and alcoholic beverages [11]. Visually PE appears red and phycocyanin range from purple (phycoerythrocyanin, R-phycocyanin) to deep blue (C-phycocyanin) and allophycocyanins are blue with a hint of green. Research in natural products of marine algae has made significant advances in recent years. Marine algae are known to produce a variety of compounds, and some of them have been shown to possess the biological activity of potential medicinal values in the last three decades (Moore, 1978; Konig et al., 1994) [12,13]. The discovery of metabolites with biological activities from seaweeds has increased significantly. Against these backdrops, this study involved the optimization studies on the extraction of PE from red algae K. alvarezii and its purification.

\section{METHODS}

\section{Collection of samples}

The live and healthy specimens of red seaweed K. alvarezii were collected from CS-MCRI, CSIR Institute, Mandapam coast, Rameshwaram, India. It was then cleaned and washed with sea water for the further processing.

\section{Extraction and purification of R-PE [10]}

The red algae K. alvarezii was taken, cut into small pieces, ground using mortar and pestle, and transferred to $250 \mathrm{ml}$ beaker. The buffer was prepared using required chemical constituents with specific $\mathrm{pH}$. Then, the buffer was added to ground seaweed and subjected to freeze, thawing $\left(-20^{\circ} \mathrm{C}, 37^{\circ} \mathrm{C}\right)$. Then, this was centrifuged at $8000 \mathrm{rpm}$ for 15 minutes. The pellet was discarded, and the supernatant was assayed for R-PE pigments by reading the supernatant at 562, 615, and $652 \mathrm{~nm}$ using spectrophotometer (Beckman, USA).

Partial purification of R-PE by ammonium sulfate precipitation The extracted R-PE pigment was subjected to $60 \%$ ammonium sulfate saturation. Ammonium sulfate was added continuously to the extracted PE until saturation point was reached along with continuous stirring at $4^{\circ} \mathrm{C}$. After overnight stirring, the PE extract was centrifuged at $8000 \mathrm{rpm}$ for 15 minutes at $4^{\circ} \mathrm{C}$. The pellet was collected and dried for further studies.

\section{Purification of R-PE by dialysis}

The dialysis of R-PE extract was performed to partially purify the pigment. The pellet obtained in ammonium sulfate precipitation was dialyzed against distilled water in dialysis bag. This was kept until the bag shrinks to achieve a purified pigment.

\section{Optimization of R-PE extraction [14]}

Optimization of R-PE extraction from $K$. alvarezii was performed with respect to different buffers, varying $\mathrm{pH}$, cell disruption technique, and freeze-thaw temperature by the following procedure.

\section{Buffer optimization}

Optimization of R-PE extraction using different buffers was carried out using sodium phosphate buffer ( $\mathrm{pH}-7.2$ ), potassium phosphate buffer (pH-7.0), sodium acetate-acetic acid buffer ( $\mathrm{pH}-6.0$ ) sodium) of $0.1 \mathrm{M}$ strength. Among the three buffers, the one with better R-PE yield was optimized for different $\mathrm{pH}$ ranges $(6.8,7.0$, and 7.2).

\section{pH optimization}

In the buffer optimization study, sodium phosphate buffer was found to be optimum for obtaining maximum R-PE yield. So for $\mathrm{pH}$ optimization study, sodium phosphate buffer was prepared with various $\mathrm{pHs}$ such as $6.8,7.0$, and 7.2 , and extraction was performed.

\section{Cell disruption optimization}

The cell disruption methods such as freeze-thaw, lytic enzymelysozyme, and sonication were employed on R-PE extraction.

\section{Freeze-thaw}

The freeze-thaw method is commonly used to lyse different type of cells. The technique involved freezing $\left(-20^{\circ} \mathrm{C}\right)$ the seaweed in a freezer and then thawing the material at room temperature or $37^{\circ} \mathrm{C}$. This method of lysis causes cells to swell and ultimately break as ice crystals form during the freezing process and then contract during thawing. Multiple cycles are necessary for efficient lysis, and the process can be quite lengthy.

\section{Lysozyme}

Lysozyme is an enzyme used to break down cell walls to improve protein or nucleic acid extraction efficiency. Lysozyme was added to the ground red algae in the ratio $2 \mu \mathrm{g} / \mathrm{ml}$. The mixture was incubated at room temperature for $24 \mathrm{hrs}$. The extraction was performed by centrifugation.

\section{Sonication}

Sonication is the third class of physical disruption commonly used to break open cells. The method uses pulsed, high-frequency sound waves to agitate and lyse cells, finely diced tissue. The sound waves are delivered using an apparatus with a vibrating probe that is immersed in the liquid cell suspension. Sonication was done for 10 minutes at high frequency. Then, this was subjected to extraction protocol.

\section{Freeze-thaw temperature optimization}

In cell disruption of optimization study, freeze-thaw method was found to be optimum for obtaining maximum R-PE yield. Hence, for freeze and thaw temperature optimization study, various freeze and thaw temperatures were employed R-PE extraction. The various freeze-thaw temperatures like that $-20^{\circ} \mathrm{C}-25^{\circ} \mathrm{C},-20^{\circ} \mathrm{C}-4^{\circ} \mathrm{C}$, and $0^{\circ} \mathrm{C}-4^{\circ} \mathrm{C}$.

\section{RESULTS}

\section{Collection of seaweeds}

The live and healthy specimens of red seaweed $K$. alvarezii were collected from CS-MCRI, Mandapam coast, Rameshwaram, India (Fig. 1).

\section{Extraction and purification of R-PE}

The seaweeds brought to the laboratory were cut into small pieces, and it was treated with buffer for the extraction of R-PE pigment. The treatment of red seaweed with a buffer was subjected to the freeze-thaw cycle. The centrifugation of the freeze-thaw samples was performed at 8000 rpm, and the red colored pigment was obtained (Figs. 2 and 3).

\section{Ammonium sulfate precipitation}

The extracted PE pigment was subjected to $60 \%$ ammonium sulfate saturation. Ammonium sulfate was added continuously to the extracted PE until saturation point was reached along with continuous stirring

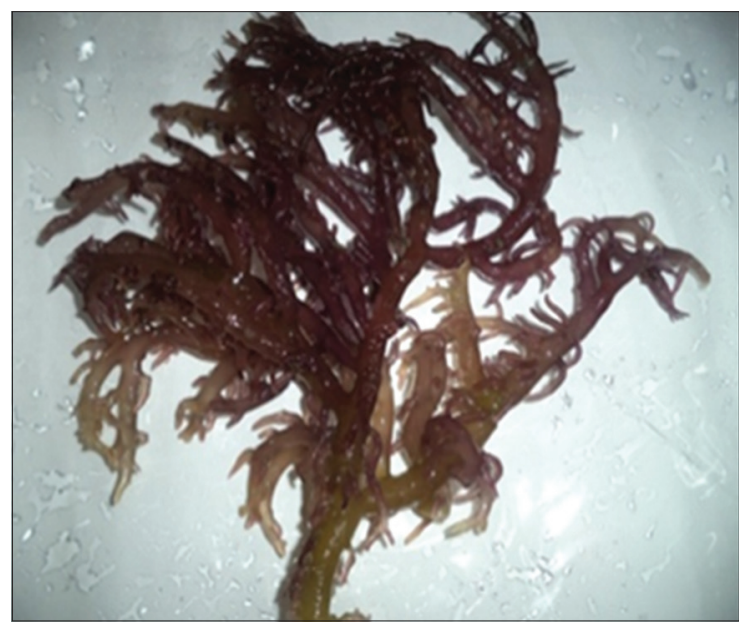

Fig. 1: Kappaphycus alvarezii (red seaweeds) 


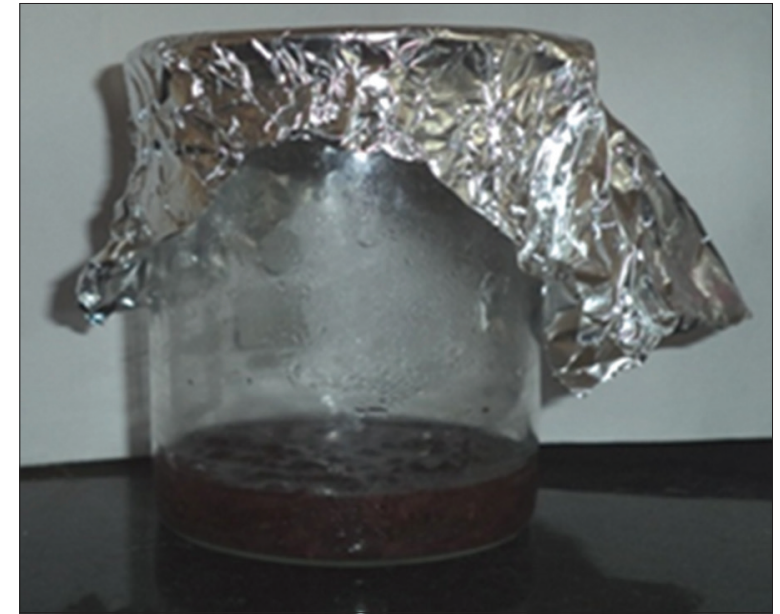

Fig. 2: Treatment of Kappaphycus alvarezii in sodium phosphate buffer

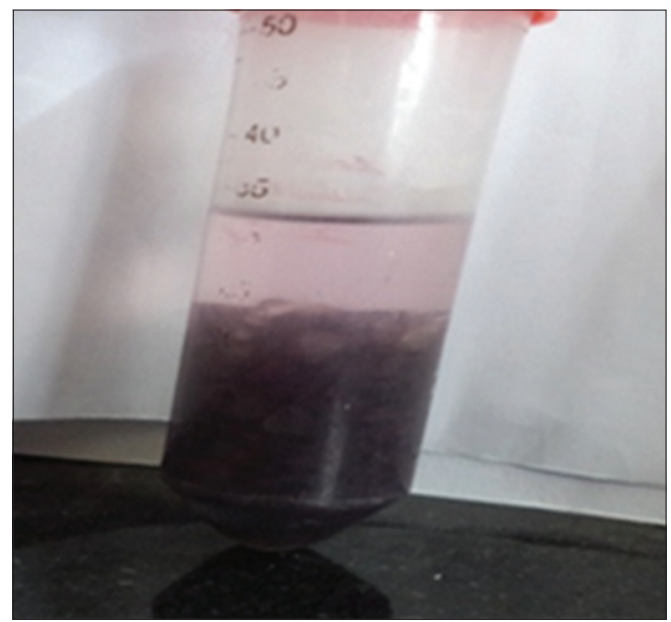

Fig. 3: Red color pigment obtained during centrifugation

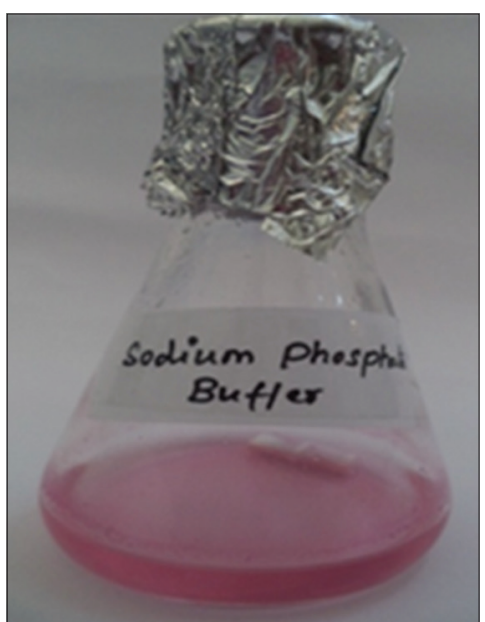

Fig. 4: The phycoerythrin pigment before $60 \%$ ammonium sulfate precipitation

at $4^{\circ} \mathrm{C}$. After overnight stirring, the PE extract was centrifuged at $8000 \mathrm{rpm}$ for 15 minutes at $4^{\circ} \mathrm{C}$ (Figs. 4-6). The pellet was collected and it was dried and taken for further studies.

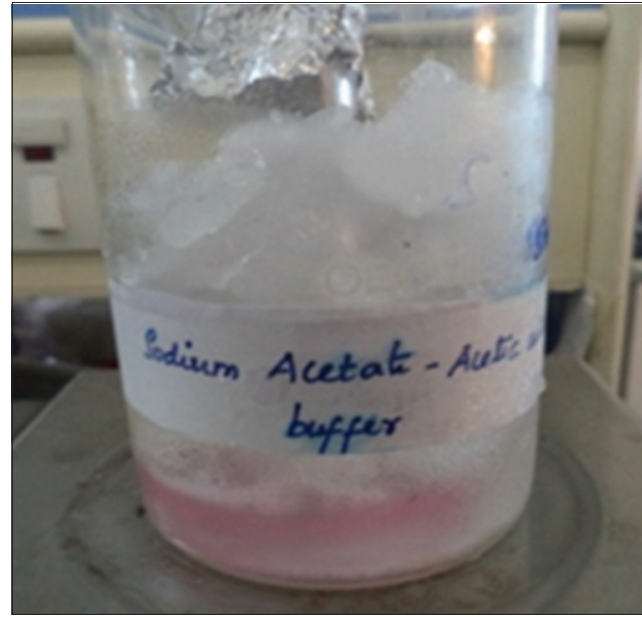

Fig. 5: Ammonium sulfate precipitation using magnetic stirrer at $250 \mathrm{rpm}$

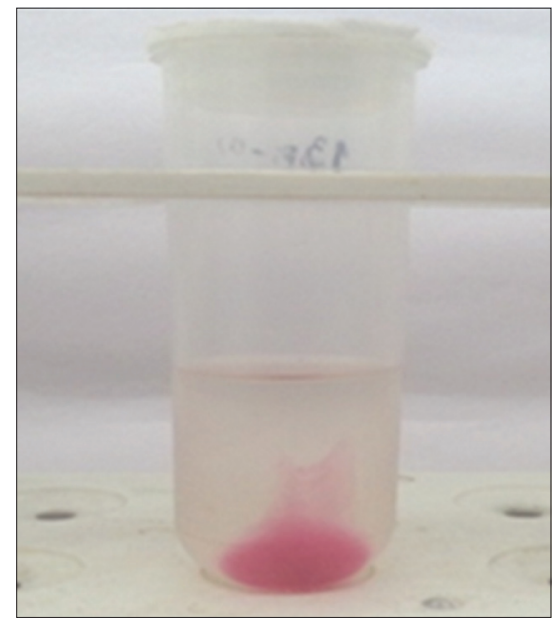

Fig 6: Phycoerythrin deposited at the bottom after centrifuging at $8000 \mathrm{rpm}$ for 20 minutes at $4^{\circ} \mathrm{C}$

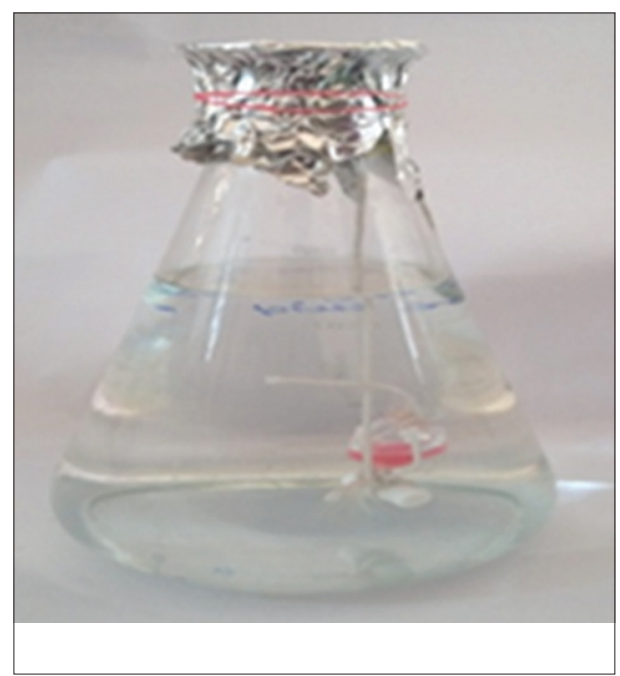

Fig. 7: Dialysis of phycoerythrin pigment against distilled water

\section{Purification of R-PE by dialysis}

The dialysis of the PE extract was performed to partially purify the pigment. The pellet obtained in ammonium sulfate precipitation was 
dialyzed against distilled water in dialysis bag. This was kept until the bag shrinks for purified pigment (Fig. 7).

\section{Optimization of R-PE extraction}

Buffer optimization

Optimization of PE extraction was performed using different buffers such as sodium phosphate buffer ( $\mathrm{pH}-7.2)$, potassium phosphate buffer (pH-7.0), sodium acetate-acetic acid buffer (pH-6.0) sodium) of 0.1 M strength. During comparison of various buffers, sodium phosphate buffer showed maximum PE production of R-PE as 0.215 OD value (Figs. 8a and 9a).
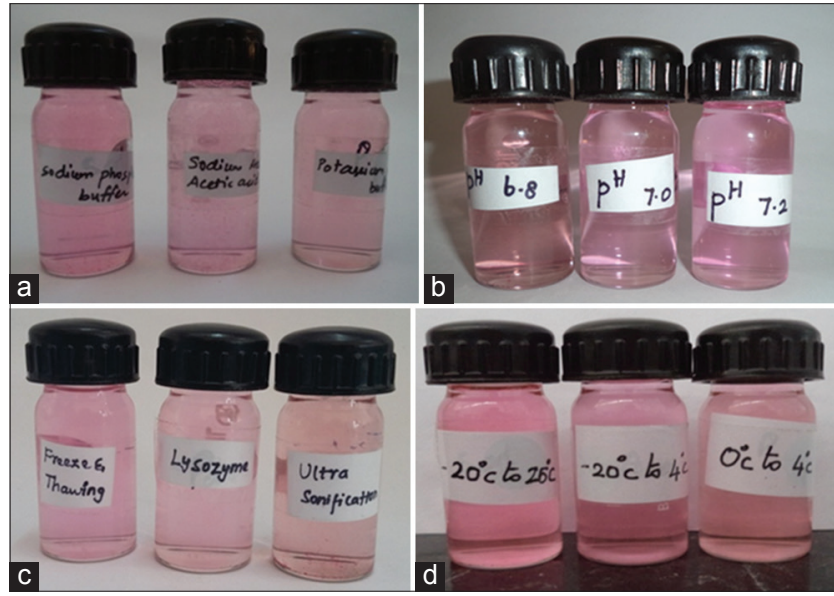

Fig. 8: (a) Optimization of phycoerythrin production using different buffers. (b) Optimization of phycoerythrin production using different $\mathrm{pHs}$. (c) Optimization of phycoerythrin production using different cell disruption methods. (d) Optimization of phycoerythrin production using different freeze-thaw temperatures

\section{pH optimization}

In the buffer optimization study, sodium phosphate buffer was found to be optimum for obtaining maximum R-PE yield. $\mathrm{pH}$ optimization was performed using sodium phosphate buffer prepared with various $\mathrm{pHs}$ such as 6.8, 7.0, and 7.2. On comparison of various $\mathrm{pH}$ used in sodium phosphate buffer, it was found that R-PE content was high at pH 7.2 and R-PE content was obtained as 0.214 OD value (Figs. $8 \mathrm{~b}$ and $9 \mathrm{~b}$ ).

\section{Cell disruption optimization}

The cell disruption methods such as freeze-thaw, lytic enzyme-lysozyme, and sonication were employed on R-PE extraction. On comparison of various cell disruption techniques for extraction of R-PE, it was found that freeze and thaw method showed maximum R-PE content of 0.210 OD value (Figs. 8c and 9c).

\section{Freeze-thaw temperature optimization}

In cell disruption of optimization study, the freeze-thaw method was found to be optimum for obtaining maximum PE yield. Hence, for freeze and thaw temperature optimization study, various freeze and thaw temperatures were employed for R-PE extraction. The freeze-thaw temperatures used in the present study were $-20^{\circ} \mathrm{C}-25^{\circ} \mathrm{C},-20^{\circ} \mathrm{C}-4^{\circ} \mathrm{C}$, and $0^{\circ} \mathrm{C}-4^{\circ} \mathrm{C}$.

On comparison of various freeze and thaw temperatures, it was found that at $-20^{\circ} \mathrm{C}$ and $25^{\circ} \mathrm{C}$ freeze and thaw, the amount of R-PE produced was maximum to be 0.441 OD value (Figs. $8 \mathrm{~d}$ and $9 \mathrm{~d}$ ).

\section{DISCUSSION}

The current study focuses on the effects of different parameters on photosynthetic pigment production of red algae such as $K$. alvarezii collected from CS-MCRI, CSIR Institute, Mandapam coast, Rameshwaram, India. Pugalendren et al. [10] described by sample was collected from the sea coast of Rameshwaram, Tamil Nadu, India, in the form of dry and living sample. K. alvarezii samples were cleaned at epiphytes and necrotic parts were removed. Samples were rinsed with sterile water to remove any associated debris. The sample was kept under sunshade for 7 days. After drying the sample, it was ground thoroughly to

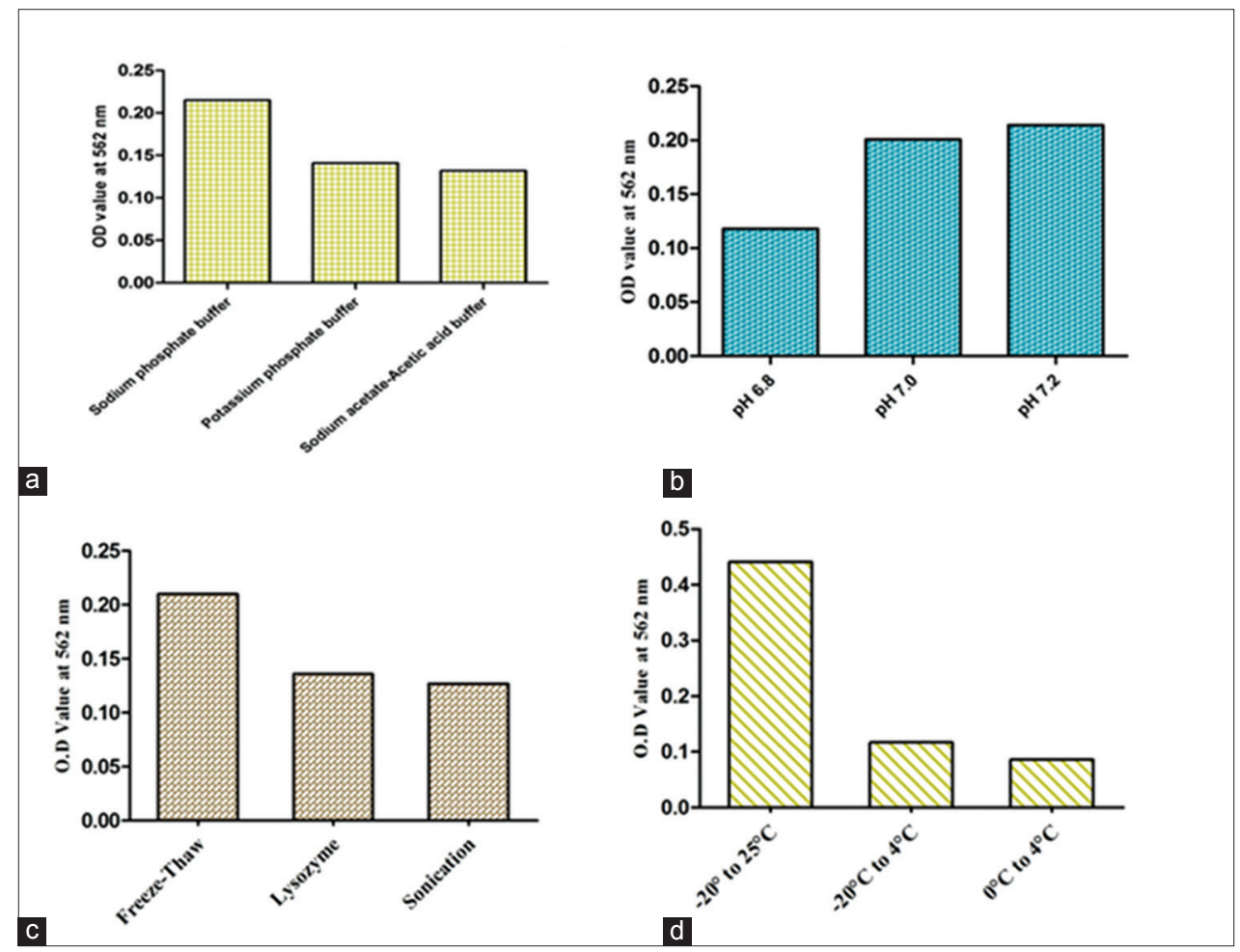

Fig. 9: (a) Effect of different buffers on R-phycoerythrin (R-PE) production. (b) Effect of different temperatures on R-PE production. (c) Effect of different cell disruptions on R-PE production. (d) Effect of different pHs on R-PE production 
powder form. The powder was then used for the primary estimation of proteins, fatty acid, carotene, sterol compounds, and antimicrobial test. Unnikrishnan et al. [15], in his article on antidiabetic potential of marine algae by inhibiting key metabolic enzymes, investigated two edible seaweeds, Sargassum polycystum and Sargassum wightii for their antidiabetic potential using in vitro enzyme inhibitory assays.

Rajasulochana et al. [6] explained by the live and healthy specimens of red seaweed $K$. alvarezii were collected along the coast of Mandapam (Lat. 090 17'N; Long. 790 08'E), Palk Bay, Tamil Nadu, between January 2009 and March 2010 and brought to laboratory. It was then cleaned and washed with tap water for the extraction of R-PE. The R-PE obtained was used to analyze the physico-chemical properties.

Indriatmoko et al. [16] red algae K. alvarezii (Doty) Doty ex P.C. Silva var. brown and var. green were cultivated in Sumenep seashore ( $\pm 50 \mathrm{~m}$ from coastline), Padike village, Talango Island, Madurai, East Java (S 75'18.0636", E 11356'20.1804"). It was studied on the composition of photosynthetic pigments in red algae $K$. alvarezii cultivated in different depths.

Pugalendren et al. [10] extracted the red algae $K$. alvarezii was taken in a sterile container and kept in sodium phosphate buffer (pH 7.2; $0.1 \mathrm{M}$ ) for repeated freeze and thawing. Later, the biomass was separated by centrifugation at $8000 \mathrm{rpm}$ for 15 minutes. The proteins in the supernatant were precipitated with $60 \%$ ammonium sulfate saturation and the mixture was stirred overnight. The PE, phycocyanin, and allophycocyanin pigments were assayed by reading the supernatant at 562,615 , and $652 \mathrm{~nm}$ using DU-40 Spectrophotometer (Beckman, USA). Fractions which show a higher reading for R-PE (562 nm) were pooled. All the subsequent purification steps were carried out at $4^{\circ} \mathrm{C}$. The R-PE obtained was used to analyze the physico-chemical properties.

The analyses of PE carried out by Yokoya et al. [17] revealed that proteins of the red, green, and brown pigments pointed to significant differences only between the red and green pigments pointed to significant differences only between the red and green pigments $(\mathrm{p}<0.001)$, a finding that suggests different acclimatization strategies. The red pigment had the highest concentration and the green pigment the lowest. These pigments also showed a slight difference in phycocyanin and chlorophyll concentrations in some months. These results corroborate those of earlier studies using color variants of other species of Rhodophyceae.

Chia et al. [18] studied the in vitro antioxidant, antiproliferative, genotoxic, and cytoprotective effects of the methanolic extract of the seaweed Padina tetrastromatica were assayed using the 1,1-diphenyl-2-picrylhydrazyl radical, superoxide, nitric oxide and hydroxyl radical scavenging assays, 3-(4,5-dimethylthiazol-2-yl)-2,5diphenyltetrazolium bromide and comet assays.

Velkanni and Rengasamy [19] had estimated the photosynthetic pigments such as chlorophyll a, R-PE, R-phycocyanin, and allophycocyanin on different concentrations of nitrate on the red algae Hypnea valentiae. However, the correlation to environmental parameters particularly light intensity which is the major factor in governing and altering the absorption spectra of pigments had not been recorded by them.

In the study carried out by Saenger et al. [20], the R-PE was optimized in different parameters and its PE yield. Phycobiliproteins such as R-PE, R-phycocyanin, and allophycocyanin among which R-PE were found to be a dominant pigment. However, there was an additional red pigment called floridorubin recorded by in the red alga Lenormandia prolifera, in addition to R-PE.

The investigated experimental design done by Dumay et al. [21] indicated that the highest extraction of R-PE yield has obtained at the optimal conditions of the independent variable are $12^{\circ} \mathrm{C}$ (temperature), $6.45(\mathrm{pH})$, and $13.18 \mathrm{mg} / \mathrm{g} \mathrm{dw}$ (E/S ratio). The effect of the parameters for R-PE extraction yield has three dimensional graphs. This software indicates about $72.31 \%$ desirability. This mean that the high value of desirability demonstrates good reliability and indicates also here the cumulative robustness of all the factors studied.

\section{CONCLUSION}

Intensive investigation was made on the R-PE from the red algae $K$. alvarezii. The study revealed that R-PE can be effectively extracted using sodium phosphate buffer at $\mathrm{pH} 7.2$ by the freeze-thaw method. The further results on purification and testing the efficacy of PE as a food colorant and cosmetics will make PE a potential candidate for commercial applications in food and cosmetic industries.

\section{REFERENCES}

1. De Barros-Barreto MB, Marinho LC, Reis RP, Da Mata CS, Ferreira PC. Kappaphycus alvarezii (Gigartinales, Rhodophyta) cultivated in Brazil: Is it only one species? J Appl Phycol 2013;25(4):1143-9.

2. Ask E, Batibasaga A, Zertuche-Gonzalez J, De San M. Three Decades of Kappaphycus alvarezii (Rhodophyta) Introduction to Non-endemic Locations. Proceedings of International Seaweed Symposium; 2003. p. $49-57$

3. Machado S, Brijesh K, Troy D. Ostreasterol. Seaweed Sustainability: Food and Non-Food Applications. Vol. 4. London, UK: Elsevier; 2004. p. $402-12$

4. Mc Hugh DJ. A Guide to Seaweed Industry. FAO Fisheries and Aquaculture Technical Paper. T441; 2003. p. 118.

5. Kumar SK, Ganesan K, Rao SP. Antioxidant potential of solvent extracts of Kappaphycus alvarezii (Doty) Doty - An edible seaweed. Food Chem 2008;107(1):289-95.

6. Rajasulochana P, Dhamotharan R, Krishnamoorthy P. Primary phytochemical analysis of Kappaphycus sp. J Am Sci 2009;5(2):91-6.

7. Fayaz M, Namitha KK, Murthy KN, Swamy MM, Sarada R, Khanam S, et al. Chemical composition, iron bioavailability, and antioxidant activity of Kappaphycus alvarezzi (Doty). J Agric Food Chem 2005;53(3):792-7.

8. Omer TA. Isolation and identification of some chemical constituents in two different types of fresh water macro algae in Bestansur village in Suleiman city Kurdistan region (North Iraq) by HPLC techniques. IOSR J Appl Chem 2013;4(3):45-55.

9. Dunford NT, King JW. Phytosterol enrichment of rice bran oil by a supercritical carbon dioxide fractionation technique. J Food Sci 2000;65(8):1395-9.

10. Pugalendren S, Sarangam B, Rengasamy R. Extraction of R-phycoerythrin from Kappaphycus alvarezii (Doty) Doty ex Silva and analyses of its physico-chemical properties. J Acad Ind Res 2012;1(7):2278-5213.

11. Sekar S, Chandramohan M. Phycobiliproteins as a commodity: Trends in applied research, patents \& commercialization. J Appl Phycol 2008;20(2):113-36.

12. Moore RE. Algal non-isoprenoids. In: Scheuer PJ, editor. Marine Natural Products, Chemical and Biological Perspective. New York: Academic Press; 19781. p. 44-171.

13. Konig GM, Wright AD, Sticher O, Anghofer CK and Pezutto JM. Biological activities of selected marine natural products. Planta Med. 1994;60:532-7.

14. Hemlata, Pandey G, Bano F, Fatma T. Studies on Anabaena sp. NCCU-9 with special reference to phycocyanin. J Algal Biomass Utln 2011;2(1):30-51.

15. Unnikrishnan PS, Suthindhiran K, Jayasri MA. Antidiabetic potential of marine algae by inhibiting key metabolic enzymes. Front Life Sci 2015;8(2):149-59

16. Indriatmoko, Heriyanto, Limantaraa L, Hardo T, Brotosudarmoa P. Composition of photosynthetic pigments in a red algae Kappaphycus alvarezii cultivated in different depths. Proc Chem 2015;14(2):193-201.

17. Yokoya NS, Necchi O, Martins AP, Gonzalez SF, Plastino EM. Growth responses and photosynthetic characteristics of wild and phycoerythrindeficient strains of Hypnea musciformis (Rhodophyta). J Appl Phycol 2007;19:197-205.

18. Chia YY, Kanthimathi MS, Rajarajeswaran J, Khoo KS, Cheng HM. Antioxidant, antiproliferative, genotoxic and cytoprotective effects 
of the methanolic extract of Padina tetrastromatica on human breast adenocarcinoma and embryonic fibroblast cell lines. Front Life Sci 2014;8(4):411-8.

19. Velkanni K, Rengaswamy R. Effect of nitrate on growth, pigments and k-carrageenan contents of Hypnea valentiae (Turn.) Mont. Mahasagar 1992;52(4):150-62.
20. Saenger $\mathrm{P}$. The water soluble pigments of the red algae, Lenormandia prolifera. Phycologia 1969;7(1):59-64.

21. Dumay J, Morançais M, Munier M, Le Guillard C, Fleurence J. Phycoerythrins: Valuable proteinic pigments in red seaweeds. Advances in Botanical Research. Vol. 71. Ch. 11. Burlington: Academic Press; 2014. p. 321-43. 